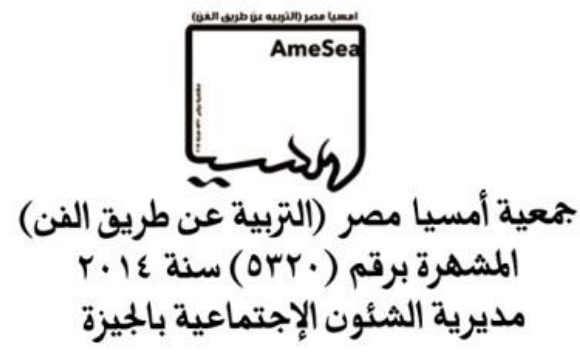

\title{
The Social Integration and Digital Inclusion through Art and Communication in Community
}

Estrella Luna Muñoz

Lisbon University

Researcher and creator of projects of educational innovation, art, culture, and social community integration 


\begin{abstract}
The objective of this research project is focused in how to generate learning, social and digital inclusion through Art and Communication.

Starting from a fundamental question: how to promote social and digital inclusion within disempowered communities lacking social and technological resources?

We observe that is urgent to modify the structure of formal and non-formal educational environments, using the art and communication in order to create different ways of interaction, learning, active participation and the skills that are needed for the 21 st Century.
\end{abstract}

Taking a Participatory Action Research methodological approach, the empirical field of the qualitative study is based in different neighborhoods in Portugal, Mexico and Cabo Verde with young people; where was used as data collection and analysis resources the focal group interviews, the products make by the group, field notes and reports.

The activities consisted in the creation of videos, community interviews, stories, cartographies, street games, newspapers, digital animations, collective magazines and games with QR codes, among others.

This study aims to define principles and guidelines for community work to develop media and information literacy with art, communication, games and collective experiences like alternative strategies to generate knowledge and integration.

Create dialogue among young people and with the community is essential to engage them. Build in this way a network of collective learning, is a key to generate current and future social change as well develops a lifelong learning.

Keywords: communication, arts, social integration, digital inclusion, community

\title{
Contextualization
}

Currently young people can connect to the Internet, learn and study at any time or place, but what about communities or environments with few technological resources or that are in risk at exclusion (social / educational / digital)? How can we promote social integration and digital inclusion?

In 2008 the United Nations Educational, Scientific and Cultural Organization (UNESCO) and a group of specialists decided to group the main current global needs around ICTs and education with the term Media and Information Literacy (MIL), defined as:

(...) the essential competencies (knowledge, skills and attitude) that allow citizens to engage with media and other information providers effectively and develop critical thinking and life-long learning skills for socializing and becoming active citizens.

(Wilson, C., Grizzle, A., Tuazon, R., Akyempong, K., \& Cheung, C., 2011, p. 187) 
The differences between generating only a digital inclusion goes beyond just knowing how to work with media in a technical way, but being critical and active in the processes of analysis and creation of information. Competencies that are essential for this era of transformations.

Thus, the problem of many projects in vulnerable sectors that have failed is because they only focus on carrying technological infrastructure without having monitoring programs and not being attractive to its population. Because if we question ourselves, are we really teaching young people how to analyze information or how to use technology? Do we really know how to analyze and be critical of the media information with which we live? How can we create this in a creative and attractive way for young people?

In many cases and as mentioned by Gregorio Luri (Luri, 2014), the school is always favors the one who has the most, a citizen with a middle or high class can have selection alternatives in their education, but those with low resources this is impossible. For these reasons it is important to generate actions in non-formal educational settings, since for some excluded people, these places may be the only ones or the few spaces where they can acquire an apprenticeship.

We must start today, promote activities so that children and young people will be digital citizens, active subjects with critical thinking and will create knowledge and learning both inside and outside the school. "Individual children's growth and development is the basis for a country's development" (Yoshikawa, 2015).

Integration between art and community

The Wagner and Kozma project (Wagner, DA, \& Kozma, R., 2003) on the use of information and communication technologies in education in poor populations, argues that the main problem in computer literacy is the quality of the programs in its relation to the needs of young people and adults. That is why one of the keys is to always work with the context, concerns and needs of the communities where it is intended to intervene.

Implementing art, communication and integration activities to encourage community work used in past projects in Mexico, Cabo Verde and now in Portugal have gradually helped to break the digital and social gaps that exist in these sectors. This is one more step to generate a global development in the future, promoting identity union for a better integration in the environment of young people.

Thus, together with these strategies, the activities implemented in this project are focus on the educational, communicative and artistic aspects that together with technology work on the theme of identity as well as constant the work with the community.

The work sessions with the young people are composed of eight central activities, among which include photo editing, videos and interviews for journalistic and communicative purposes; creation of stories, legends and animations for artistic and creative purposes; mapping of the collective space together with the community, for purposes of 
social integration and identity strengthening; and creation of games with QR codes, to create group interaction and teamwork.

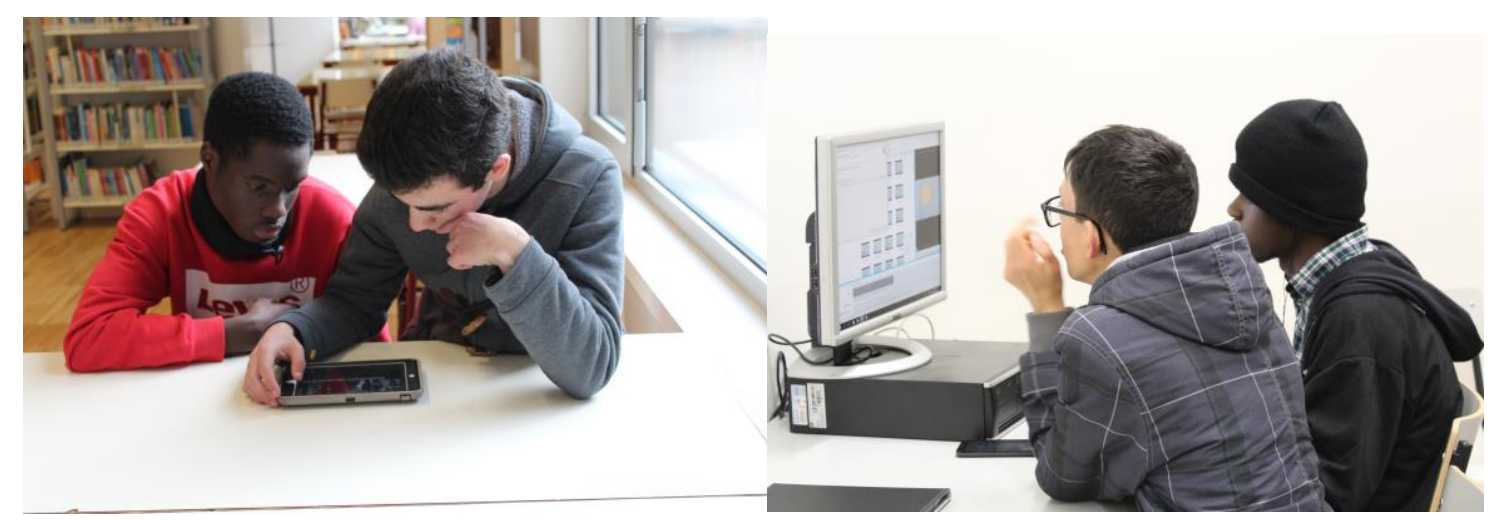

Figure 1. Work with digital animations, news, video and photo editing with computers, tablets and cellphones

The selection of each of these dynamics arose from previous work in diverse environments with young people and children from multicultural backgrounds. From this experimentation and previous research, the dynamics were also shaped to help develop some of the necessary skills of the 21 st Century. These skills are some that young people need to have access and participation in social processes like: work in multidisciplinary teams, interact with the community developing democratic values, work with freedom of creation, empower themselves through critical and reflective debate, generate divergent thinking, solve problems in a creative way and cultivate projects based on the needs of the community.

In the process of carrying out these activities, we work with three essential lines of action: art and communication as a way of generating knowledge; play as an alternative strategy of interact and learn; and connectivity through the exchange of social, identity and collective experiences.

With these lines of action, we seek to modify the traditional structure of learning and the idea of what intelligence is. We work with young people to transform the way of seeing and transmitting knowledge, since it can be found anywhere and anyone can teach it.

Intelligence is not use the memorization or has good grades in college or university. Intelligence is formed from experiences, are the dynamics that are generated in the environment with the other, with their social and cultural environment. It is also know how to propose and analyze multiple solutions in any area of study, be multidisciplinary, have an open mind to changes and be able to modify the ways of structuring and creating things. 

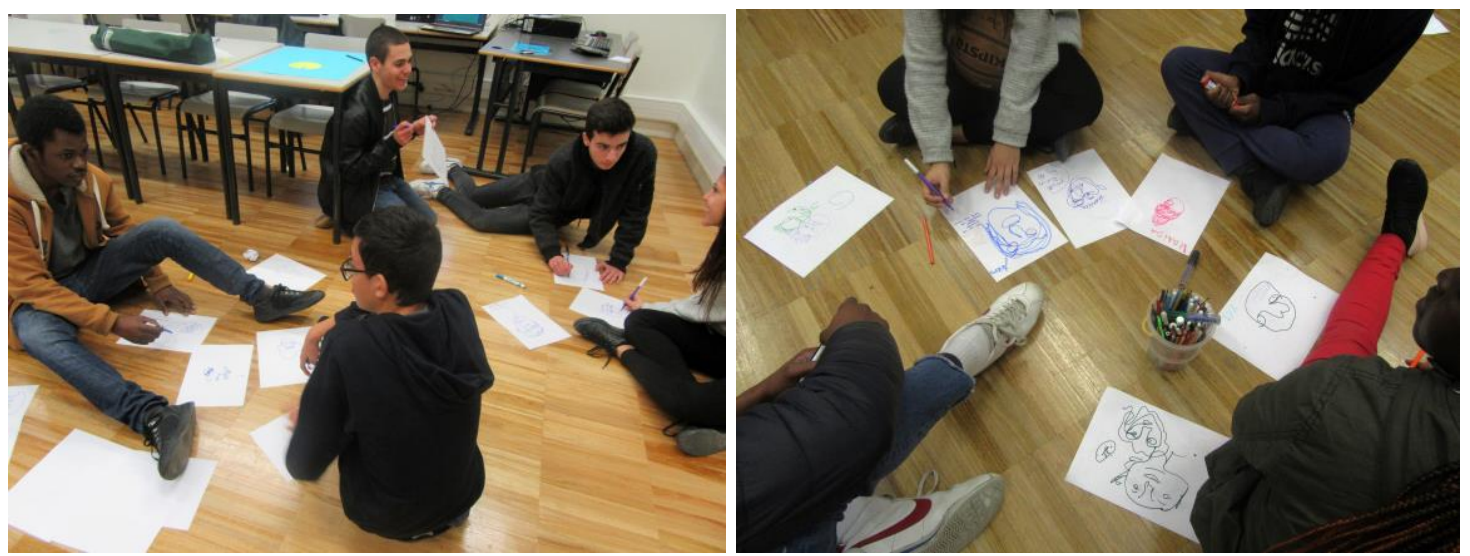

Figure 2. Integration activities in group, creating drawings and stories

As we observed in the generational stages, the new environment demands multicultural citizens, wanting to learn and innovate; but this motive is necessary to encourage strategies of adaptability, to create solutions to problems, create alternatives and be adapted in this way to the changes that are constantly generated in our global environment.

Also like Ken Robinson mentions that the key to transforming education is not to standardize it, but to personalize it, the key is to discover and develop the individual talents of each child or young people to guide them in the environment that they want to learn.

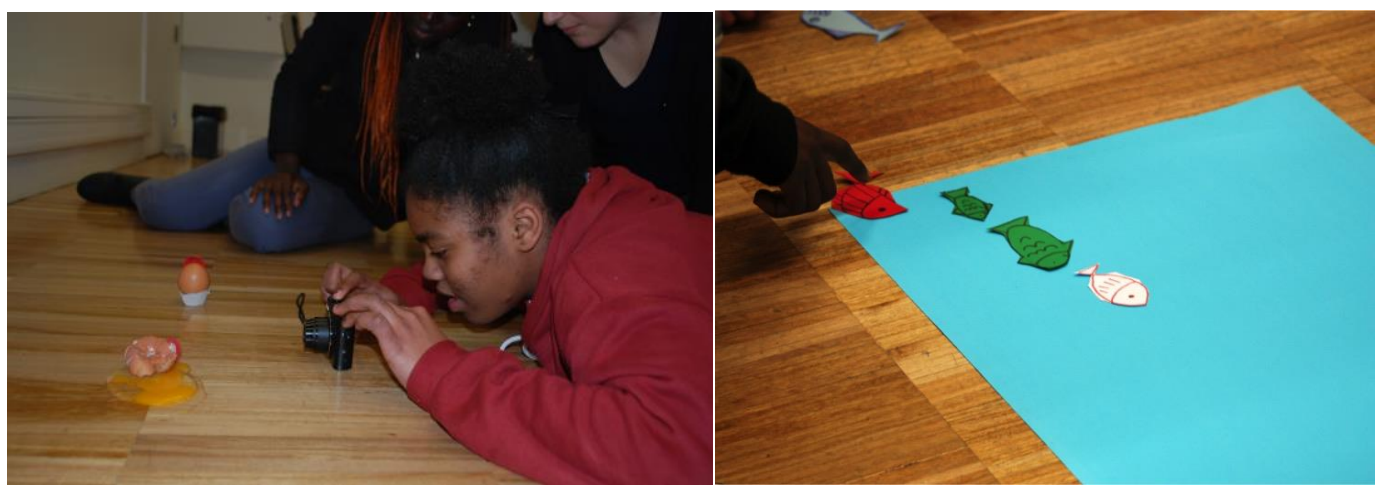

Figure 3. Creation process in the digital animation

The theme of identity and the simultaneous work with its locality is also essential, in order to create digital citizens and critical of their own information as a community and in this way became aware of their role as active creators of their own culture.

In each of the actions, we always sought to work from the observation and interactions of the social environment in which they were intervening, delimiting the interests and needs of young people in their community. In this way, identities are gradually reinforced to minimize the social boundaries that exist in many of their environments.

The identities are those that are built by the memory of our peoples, in the articulation of what we were, with what we are and what we will be or vision that we want to be. It is 


\section{Running head: THE SOCIAL INTEGRATION AND DIGITAL INCLUSION THROUGH ART AND COMMUNICATION IN COMMUNITY}

essential to teach how to navigate and build their identities and imaginaries, with their traditions and with the cultural practices of the place where one lives.

As Francisco Jarauta says:

... cultural identities are never something that is given, but are built collectively on the basis of experience, memory, tradition, as well as a wide variety of cultural, social, and political practices. This process must be thought historically, that is, from the system of relationships that have defined the different cultural worlds, sometimes disinterested to show the logic of their own identities and imaginary.

(AMAVI, 2000, p. 16)

For this reason, these dynamics, such as creating videos, interviews, games and thinking from the community, can function as tools that, in addition to show the look of the youth of their communities, keep alive the collective cultural identity derived from community knowledge.

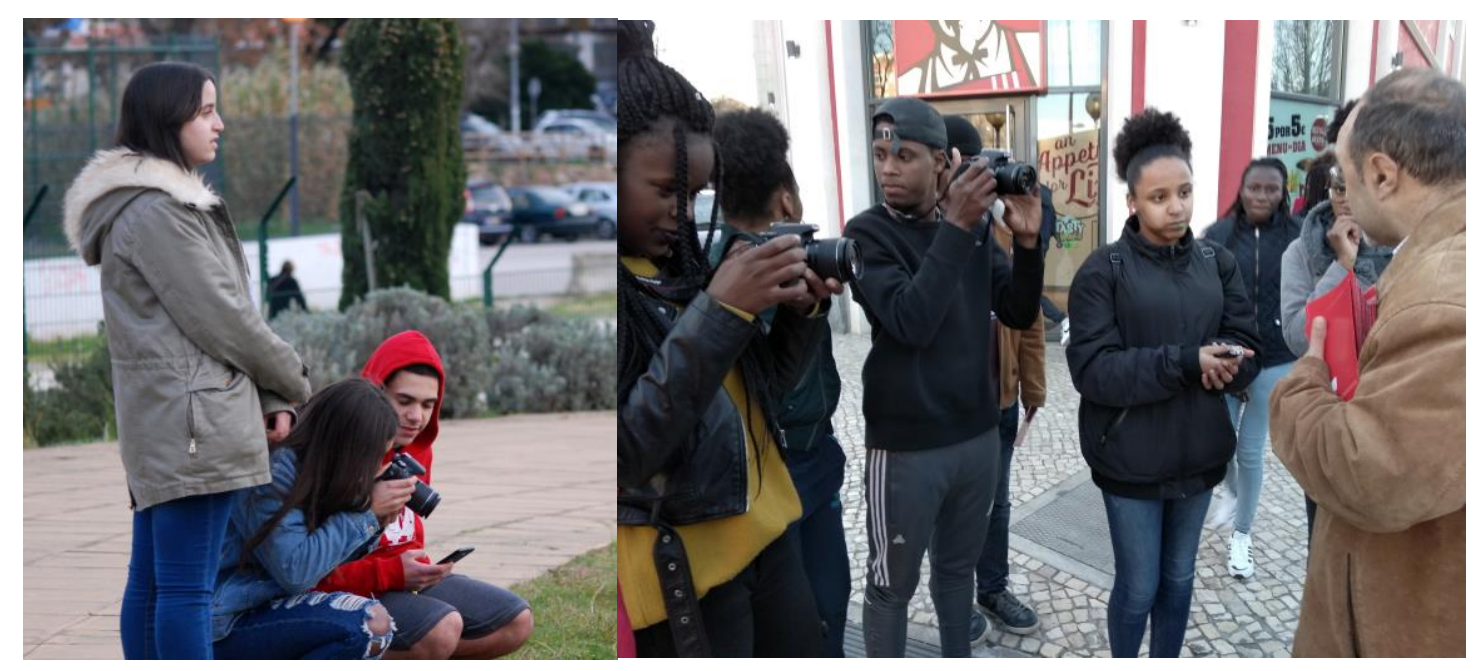

Figure 4. Activities with the community, Derive, interviews, photographic and video documentation

\section{Methodology}

The study group consisted of 20 young people, girls and boys between the ages of fourteen and eighteen years old, with school and integration difficulties, coming from African, Cape Verdean and Portuguese families.

The activities were carried out in the municipality of Amadora in Lisbon Portugal, an area characterized by its multiculturalism and being considered a problematic neighborhood with areas of low economic resources.

From Participatory-Action-Research (PAR) based on participation and research with the members of a community (Kemmis \& McTaggart, 2007), we sought to identify and strengthen social structures, processes and knowledge with the community; thus encouraging 


\section{Running head: THE SOCIAL INTEGRATION AND DIGITAL INCLUSION THROUGH ART AND COMMUNICATION IN COMMUNITY}

the construction and integration of knowledge and exchange actions among all the participants and collaborators of the action process, resulting in a collaborative process.

The action process, design and research phases were focused on the constant transformation cycles: Planning; Action-observation of the processes and implementation of the activities; Observation of the dynamics; Reflection on these processes and reactions; Analysis and re-planning...

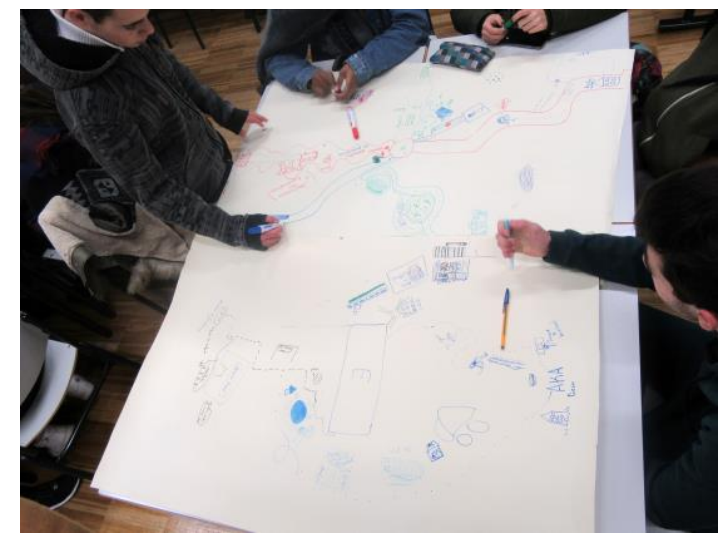

Figure 5. Planning, observation and reflection process of the activities with the young people and the team

Being a qualitative study and with cycles of observation, action and collective transformation, the data collection and analysis resources to be used were: where was used as data collection and analysis resources the focal group interviews, the products make by the group, field notes and reports.

Being used in turn as instrumental resources, three scripts, one for observation and two for interviews with the three mediators who helped in the activities.

\section{Preliminary results and conclusions}

We observe that is necessary to change and amplify the structure of formal and nonformal educational environments, using the art and communication in order to create other ways of interaction, learning and active participation.

"Current art is an inexhaustible source of knowledge on all levels: psychological, emotional, cultural, experiential (...) etc" (AMAVI, 2000, p. 200).

The points used in the activities of the present participatory action research, which have been essential for the development of the skills acquired in the young people were:

${ }^{\circ}$ Promote art and creativity as one of the important points for the development of knowledge and learning.

- Encourage the stimulation of the cognitive and emotional capacity of young people.

${ }^{\circ}$ Implement learning from experience and creation processes.

${ }^{\circ}$ Use and create new games as a strategy of interaction and shared knowledge. 
- Work with individual and collective identity as a key communication and connectivity point for the formation of each young person.

- Design work environments where various tools, media and collective structuring are used integrating and dynamic.

${ }^{\circ}$ Generate active participation and self-expression from the stimulation of reflection and dialogue.

${ }^{\circ}$ Working with error as a tool for analysis, creation and transformation in activities.

${ }^{\circ}$ Work in a multidisciplinary way and from the creation of projects.

As artists, teachers or students, we can use the arts, communication as tools for learning, focused on supporting multicultural social groups, with problems of exclusion or integration. Being this essential for the development of a country, we have to look at and create methods to reach areas and people who do not have the same opportunities.

As a result, it is important to emphasize the importance of overcoming barriers to the proper functioning of integration within communities, that is, through strengthening identity as a cultural medium, as well as using art communication and cooperation in them.

Participating in our society is the fundamental basis for generating change. Realize the importance of being part of a community by making our culture and identity stronger.

This is one of the ways in which alternative mechanisms or methodologies can be used to develop social integration or digital inclusion always with the active participation of the young people.

Bibliographic references

AA.VV. (2003). Práctica artística y políticas culturales: algunas propuestas desde la universidad. Murcia, Spain: Editorial Universidad de Murcia.

AMAVI Asociación Madrileña de Artistas Visuales. (2000). El aprendizaje y la enseñanza del arte. Madrid, Sapin: Editorial AMAVI.

Canclini, N., Cruces, F., Urteaga, M. (2012). Jóvenes, culturas urbanas y redes digitales. Madrid, Spain: Fundación Telefónica \& Ariel.

Carlsson, U., \& Hope, S. (Ed.). (2013). Media and Information Literacy and intercultural Dialogue. MILID Yearbook 2013. Gothemburg, Sweden: UNITWIN, MILID \& NORDICOM.

Castells, Manuel. (2000). O poder da identidade. São Paulo, Brazil: Paz e Terra.

Costa, F., \& Cruz, E. (2016). Atividades para Inclusão Digital de Adultos. Lisbon, Portugal: Instituto de Educação, Universidade de Lisboa.

Cuevas, A., \& Simeão, E. (2011). Alfabetización informacional e inclusión digital. Hacia un modelo de infoinclusión social. Revista Interamericana de Bibliotecología, 34 (3), $335-341$.

Engeström, Y. (1987). Learning by expanding: An activity-theoretical approach to developmental research. Helsinki, Finland: Orienta-Konsultit. 
Kemmis, S., \& McTaggart, R. (2007). Participatory Action Research: Communicative Action and the Public Sphare. Strategies of Qualitative Inquiry, 271-330.

Lens, J. (2008). La incorporación de propuestas, enfoques, marcos teóricos y modelos actuals de educación no formal y comunitaria a la formulación e implementación de proyectos y programas educativos socailes. Buenos Aires, Argentina: Universidad Tenológica Nacional.

Torres, C., \& Pareja, J.A. (2007). Educación No formal y Diferenciada. Fundamentos didácticos y organizativos. Madrid, Spain: CCS.

UNESCO. (2012). Lucha contra la exclusión en la educación. Guía de evaluación de los sistemas educativos rumbo a sociedades más inclusivas y Justas. Paris, France: UNESCO.

Wagner, D. A., \& Kozma, R. (2003). New technologies for literacy and adult education: A global perspective. Filadelfia, USA: International Literacy Institute, University of Pennsylvania.

Wilson, C., Grizzle, A., Tuazon, R., Akyempong, K., Cheung, C. (2011). Alfabetización mediática e informacional. Curriculum para profesores. Quito, Ecuador: UNESCO.

Yoshikawa, H. (2015). La educación preescolar universal para los niños de cuatro años podría beneficiar a todos. División de protección Social y Salud del Banco Interamericano de Desarrollo. Retrieved from http://blogs.iadb.org/desarrolloinfantil/2015/01/12/educacion-preescolar/

Zubieta, J., Bautista, T., Gómez, A., Freixas, M. (2015). Educación. Las paradojas de un sistema excluyente. Mexico City, Mexico: Universidad Nacional Autónoma México, Instituto de Investigaciones Jurídicas. 